\title{
VALUE-CHAIN DEVELOPMENT FOR RURAL POVERTY REDUCTION: A REALITY CHECK AND A WARNING
}

\section{Dietmar Stoian, Jason Donovan, John Fisk, and Michelle F. Muldoon}

\section{Introduction}

In the late 1990 s, a sense of urgency over the need to reinvigorate development processes led to the formulation of the Millennium Development Goals, which incorporated the view that increased income is a prerequisite to livelihood security and a decent standard of living. To date, however, notable progress in poverty reduction-measured in terms of income and passing the US $\$ 1$ a day absolute poverty threshold — has mainly been made in Southeast and East Asia, especially China, while significant poverty pockets continue to persist in the rural areas of Africa south of the Sahara, and in South Asia, and Central and South America (UN 2011). In search of viable alternatives to reducing poverty, value-chain development (VCD) emerged in the early 2000 s as (1) a market-based approach to meet poverty-related Millennium Development Goals, and (2) a response to new opportunities in international markets signaling stronger demand for agricultural and forest products and services produced with environmental and social responsibility.

VCD has generally been defined as an "effort to strengthen mutually beneficial linkages among firms so that they work together to take advantage of market opportunities, that is, to create and build trust among value chain participants" (Webber and Labaste 2010). Key concepts related to VCD are win-win relationships, upgrading, innovation, and added-value. From a macroeconomic perspective, VCD may be promoted with a view to the competitiveness of a given sector or subsector. From a microeconomic perspective, VCD may target marginalized actors in the upstream segments of a value chain. Such "pro-poor" VCD has been defined as a "positive or desirable change in a value chain to extend or improve productive operations and generate social benefits: poverty reduction, income and employment generation, economic growth, environmental performance, gender equity 
and other development goals" (UNIDO 2011). It is principally from the latter perspective that many development agencies, donors, and governments have adopted VCD as a key element of their rural poverty-reduction strategies (see DFID and SDC 2008; Humphrey and Navas-Alemán 2010). In addition to targeting poor and vulnerable populations in the rural sector as primary beneficiaries, some value-chain initiatives seek to link to the macroeconomic environment by broadening their approach toward resource-constrained enterprises in the upstream segments of a value chain, and the promotion of changes in the political-legal, institutional, and regulatory frameworks (see Kula, Downing, and Field 2006).

Despite the prominent role of the VCD approach in current development agendas, surprisingly little is known about its impacts on rural poverty. The urgency of making tangible progress toward the poverty-related Millennium Development Goals and the uncertainty about the actual and potential contributions from VCD call for taking stock in terms of what we already know about its design, implementation, and impact; and what we have yet to learn to direct growing investments in such initiatives and ensure substantial effects on poverty. In this chapter, we first present those claims regarding VCD that are backed by clear evidence or broad consensus ("what we know"), followed by a discussion of issues where more evidence and consensus are needed ("what we think we know"). Next, we examine those questions where current knowledge falls short and where innovative action is needed ("what we still need to know and do differently"). We conclude with a call for an asset-based approach to design, implementation, and assessment of VCD and the need for nonmarket interventions to help particularly disenfranchised groups to meet the minimum asset thresholds for their successful participation in VCD.

\section{What We Know}

Actors promoting VCD vary widely, as do their motives. NGOs often pursue explicit poverty-reduction goals, while the private sector may see them as a by-product.

The strengthening of mutually beneficial business relationships between two or more chain actors, including producers, distributors, processors, wholesalers, and/or retailers, requires improved interactions between them, often facilitated by the provision of technical, business, and financial services from outside of the chain. Related interventions aim at strengthening 
capacities and enhancing mechanisms for sharing information, benefits, and risks. The stronger the win-win nature of such relations, the more likely they are to endure over time. While pro-poor value-chain initiatives have an explicit focus on poverty reduction, other value-chain initiatives may not. This, however, does not mean that they could not have an important, though unintended, poverty impact. Further, in many cases a diverse set of stakeholders from within and outside of the value chain invest in the chain, at times with little or no coordination between them. Private companies, for example, may invest in their relationships with poor producers to improve their environmental and social credentials, while an NGO may provide technical and financial assistance to the producers and other chain actors. From the company's perspective, VCD is one among several types of business strategies pursued to ensure a positive image, market positioning, and the sourcing of scarce raw materials (Box 2.1). From the NGO's perspective, their work with upstream chain actors is in explicit pursuit of povertyreduction goals.

\section{$V C D$ involving the poor needs to account for their diversified livelihood strategies} and related risks and trade-offs.

A review of value-chain methodologies and case studies (see, for example, Kula, Downing, and Field 2006; Tanburn and Sen 2011) shows that the poverty-reduction potential of VCD is often based on the assumption that poor households (1) have sufficient resources to effectively participate in VCD, (2) do not face substantial trade-offs when using these resources, and (3) are able to assume higher risks when reinvesting capital and labor. In reality, however, many poor households pursue diversified livelihood strategies by combining subsistence and market-oriented agriculture with off-farm labor and other nonagricultural income-generating activities. In the attempt to spread risk and smooth incomes, they optimize their overall livelihood system rather than one of the subsystems (for example, coffee production). In contrast, the participation in VCD often requires them to pursue a specialization strategy, with higher investments of capital, labor, and other resources in a given chain. Involving the rural poor in VCD therefore calls for a sound approach to address the complex trade-offs between income generation, food security, gender equity, sustainable natural resource management, and overall livelihood resilience.

According to empirical evidence, threats for the rural poor are much greater and opportunities more limited where the competitiveness of the domestic business sector lags far behind international standards (Altenburg 


\section{Box 2.1 Private-sector initiatives that link to the poor}

Value-chain development is but one approach to involve the poor in privatesector initiatives. An alternative approach is the base-of-the-pyramid (BoP), where large companies aim to involve the poor in markets either as providers of raw materials or as customers of affordable products. Such approaches often aim at producing more with less and ensuring longterm business viability. Concerns have been raised that BoP approaches underappreciate heterogeneity among the poor, as well as the intricacies of participatory partnerships between transnational companies and poor communities (Arora and Romijn 2009). Other approaches go beyond economic goals by incorporating environmental and social goals. Corporate social responsibility (CSR) strategies call for exceeding legal mandates by involving ethical standards, stakeholder claims, and international norms in the business model. Pioneers of CSR have made notable investments in determining and improving their carbon, poverty, and other environmental or social footprints in pursuit of company or industry-wide goals. Lately, though, CSR has been criticized by Porter and Kramer (2011) for not being a solution as social issues remain at the periphery, not at the core. Instead, they advocate creating shared value (CSV) as a strategy to generate value for both companies and the society by reconceiving products and markets, redefining productivity in the value chain, and enabling local cluster development. The adoption of BoP, CSR, and CSV approaches signals private-sector interest in alternative ways of doing business in an era of increased competition for nonrenewable resources and unprecedented social change. These approaches share relevant features of VCD and, in theory, can facilitate asset building, generation of higher value-added, and win-win relationships involving the rural poor. However, more critical analysis and mutual learning are needed to ensure that economic, social, and environmental goals are adequately addressed, and that trade-offs encountered along the way will be minimized through continuous improvement.

Source: Authors

2007). Under these conditions a "multi-chain approach" to VCD, as suggested by Stoian and Donovan (2007) for agricultural and forest sectors, helps to minimize risks and maximize poverty-reduction potential by strengthening not only the most promising, often export-oriented value chain, but also a variety of domestic or regional chains to which smallholders have access. Charette (2011) argues similarly, advocating a "portfolio approach" to VCD programs that stretches across sectors, in particular where the 
agricultural sector is highly subject to price and weather shocks, and where the manufacturing and/or services sectors show strong potential for growth and development. Despite these recent conceptual advances in VCD, it is still common practice to focus on a single value chain without due attention to the impact of value-chain participation of the rural poor on overall livelihood resilience and related trade-offs. In any case, VCD is only part of achieving rural poverty reduction. A comprehensive strategy should include a complementary focus on rural infrastructure and services; food security; and local markets for traditional products, such as basic grains.

Pro-poor VCD has both advocates and skeptics. Either side lacks sound evidence to substantiate their claims.

Given the intricacies of VCD, the diverse nature and interests of the stakeholders, and a general dearth of sound evidence of related impact, it does not come as a surprise that this approach has both advocates and skeptics. The former argue that the most promising option for lifting rural people out of poverty, other than rural-urban migration, is linking poor farming households to lucrative markets through skills development and new institutional arrangements along the chain. Skeptics, on the other hand, regard VCD as unsuitable for working with the very poor, given its perceived emphasis on risk-taking and entrepreneurship, and the additional challenges faced by the very poor when responding to economic incentives (Fowler and Brand 2011). The history of stimulating export-oriented production of nontraditional agricultural products illustrates some of the challenges faced when seeking to integrate the poor into more demanding markets (although not all VCD programs target export markets). From the skeptics' perspective, such an approach may be seen as an example for failed pro-poor VCD, while advocates would hold that precisely the absence of good VCD practice has limited the impact of nontraditional agricultural export programs on poverty (Box 2.2).

When looking for evidence of the impact of poverty-focused programs, it becomes evident that "despite the pressure for measuring and reporting on results, most development agencies have in effect failed to measure and report on significant results in eradicating poverty" (Tanburn and Sen 2011). As a result, neither advocates nor skeptics can base their claims regarding the efficacy of VCD on sound impact assessment. In fact, most methodologies used for assessing the impact of VCD on poverty are fairly simplistic and yield partial information on its strengths and limitations as a pathway out of poverty. Assessments typically focus on the generation of employment 


\section{BOX 2.2 Struggles of smallholders to participate in nontraditional agricultural exports}

Beginning in the 1970s and through the 1990s, governments and donor agencies promoted nontraditional agricultural exports (NTAE) in Latin America and Africa through trade liberalization, cooperative development, export promotion, fiscal incentives, subsidized credit, technical assistance, and infrastructure development. These initiatives were often geared toward medium- and large-scale agribusinesses, while smallholders participated with varying levels of intensity without being the primary beneficiaries of NTAE interventions. In some cases, the private sector has taken the lead in organizing the production of nontraditional export products. Food processors and supermarkets in Europe and the United States have redirected part of their sourcing of raw materials to traders, processors, and producers in developing countries. There is ample evidence that the conditions for smallholder participation in NTAE were often inadequate to allow for poverty reduction, and many of them dropped out of programs due to low productivity, high input costs, falling export prices, and limited access to farming inputs and credit. In other cases, smallholders were pushed out due to their limited ability to meet the quality or volume requirements of traders and processors. Over the years, consensus has emerged that NTAE development programs lacked economic sustainability, and did not adequately address poverty or the environmental and social costs of export-oriented production by large agribusinesses. VCD today, with its focus on both supply and demand factors for the design of sustainable market linkages, responds to the lessons learned from earlier NTAE experiences. However, there is an urgent need for those that fund and implement value-chain initiatives to address the poverty implications of their interventions in a more integrated way.

Source: Authors

and income, rather than broader changes in terms of critical livelihood and business assets (see Humphrey and Navas-Alemán 2010). Resulting reports thus provide an incomplete and potentially biased picture of VCD impact on the livelihoods of the poor and the viability of smallholder enterprises of which they may be a part. For example, a given initiative may have increased the income derived from commercializing crop production, while simultaneously it had compromised household food security and induced gender inequalities in terms of labor division and decisionmaking; or a smallholder enterprise may have increased permanent staff, though increased payroll costs undercut the prices paid to producer members. 


\section{Current assessments of VCD tend to provide an incomplete picture of} their impact.

The limited utility of one-dimensional assessments follows a general trend of ineffective design and implementation of monitoring and evaluation for development interventions, including those in agriculture (Haddad, Lindstrom, and Pinto 2010). Discussions in the gray literature on private-sector development have advocated traditional logframe-based project assessment for understanding VCD poverty implications, with emphasis on enterprise rather than household-level impacts (see Tanburn and Sen 2011). While logframes and similar tools for "rigorous" planning and monitoring and evaluation may serve the reporting needs of project managers and donors, they are inappropriate for understanding complex development processes (Jones 2011), as they assume that the implementing organization can achieve the targeted outcomes and impacts on its own. The failure to adequately account for external factors, such as changes in the political-legal or market context, or the effects of value-chain interventions by others, provides an incomplete and potentially distorted picture of VCD impact. The reported impact is made more questionable if household-level impacts are deducted from enterpriselevel outcomes rather than measured.

\section{What We Think We Know}

Unlike the previous section, where we summarized views of VCD for which clear evidence or broad consensus exists, this section addresses our insights or those of others that are yet to become part of the mainstream discussion on VCD.

Conceptual models underlying pro-poor VCD tend to lack a holistic perspective. Many value-chain initiatives involving the poor are based on fairly simple conceptual models focusing on a few variables (output, employment, income, production practices, infrastructure), while minimizing or omitting other critical albeit complex factors (for example, social and human capital building, vulnerability). Such initiatives often aim for greater productivity and better prices for poor households, and the resulting increase in income is seen as a proxy for poverty reduction, if not overall development. On the upside, the simplified design of a value-chain initiative reduces both monitoring and evaluation and implementation costs, and makes the results easy to communicate across the chain and to other stakeholders. On the downside, such an approach does not recognize the full set of assets needed by poor households to effectively 
participate in VCD, nor does it address how these assets can be built over time to escape poverty and ensure livelihood resilience, or deal with the trade-offs the rural poor face when making decisions about their allocation of time and resources between a specific value chain and other livelihood activities.

\section{Poor households and smallholder enterprises require minimum assets to success-} fully participate in VCD.

Despite the warning that poor households vary in their asset levels, income flows, social networks, and abilities to cope with shocks (Fowler and Brand 2011), many value-chain initiatives treat poor rural households as a uniform stakeholder group with the same response capacity. In reality, both external factors, such as access to basic infrastructure and services, common pool resources, and social stability, as well as internal factors, such as asset endowments, interests, and power, ultimately determine the extent to which poor households are "ready" to participate in specific value chains. Similarly, the "value chain readiness" of small and medium-sized enterprises (SMEs) requires adequate policies to improve overall investment conditions, attract foreign investment, and provide better business services to increase their competitiveness (Altenburg 2007). Minimum asset thresholds for successful participation in VCD apply at both household and enterprise levels, as illustrated by an example of a coffee cooperative in Nicaragua (Box 2.3). Below these thresholds, specific, nonmarket-based interventions are needed to create the necessary preconditions for poor households and resourceconstrained enterprises to become value-chain ready.

\section{VCD stakeholders would benefit from an asset-based approach, clear impact} models, and sound metrics for understanding poverty impacts and identifying options for improved pro-poor VCD.

There is a growing consensus that conventional poverty definitions need to be broadened to take account for critical livelihood assets and vulnerability (for example, McKay 2009). These definitions allow for the endowments of and changes in human, social, natural, physical, and financial capital, and their effects on livelihood resilience. When applied in VCD, such an asset-based approach is critical to determine whether value-chain readiness is reached by meeting minimum asset thresholds. It can also prove the existence of positive feedback loops; that is, processes in which the building of one asset (for example, financial capital) leads to the building of others (for example, human or physical capital). These would be understood as indicators of broad-based and lasting impact on rural livelihoods in pursuit of well-being and resilience. 


\section{BoX 2.3 Evidence of asset thresholds for successful participation in certified coffee markets}

The Nicaragua-based coffee cooperative Soppexcca links roughly 500 smallholder producers to international buyers of certified fair-trade and organic coffee. Following the coffee crisis-a period between 1999 and 2004 when prices fell below the cost of production for many producers in Central America-donors and NGOs invested \$2.1 million in building the capacity of Soppexcca and its members to expand their output and better meet the quality demands of international buyers. Donovan and Poole (2011) assessed the changes in tangible and nontangible assets for both Soppexcca and a representative sample of its members between 2006 and 2009. For the cooperative, interventions enabled major expansion of infrastructure and processing machinery, increased coverage of its technical assistance, and increased the ability to engage with new fair-trade coffee buyers in the United States. Related investments provided an option for generating income through expanded service provision to members, and thus were considered critical for the co-op's long-term survival. Most co-op members benefitted in terms of increased income flows and greater resilience through their membership in the cooperative. Nearly a fourth of the households were able to take advantage of credit provided by Soppexcca and others to expand their landholdings, diversify their agricultural production, and/or rejuvenate their coffee plantations. However, important weaknesses and gaps in assets remained unaddressed by the interventions and by Soppexcca itself. For example, financial assets remained seriously underdeveloped during the assessment period, while long-term debt increased significantly. Extension services expanded during the period, but had difficulties in responding to members' needs. One-third of the sampled households faced major barriers to intensify coffee production, access crucial inputs and services, and increase or diversify their production of basic grains. These households tended to be strongly constrained in their endowment with or access to assets, as reflected in very small landholdings, insecure land tenure, and high dependence on off-farm income for their livelihoods. They were also more likely to have older household heads or to be headed by a female. The Soppexcca case shows that greater attention needs to be paid to the asset endowments of smallholders and the related dynamics, if VCD is to reduce rural poverty in an integrated and significant way.

Source: Authors

Despite advances in thinking about the nature and causes of poverty, most skeptics and advocates of VCD rely on a limited set of indicators and data to 
substantiate their poverty claims. The former tend to describe the limited poverty impact of VCD by focusing on either the limited relative share of benefits captured by the poor in a given chain or the exclusion of the poorest sections of the rural population. Advocates, on the other hand, argue that the contribution of VCD to poverty reduction needs to be measured as an absolute increase in income through interventions in a value chain, and that employment effects among the poor are relevant irrespective of the overall distribution of benefits. In both cases, clear impact models with plausible cause-effect relationships, or refined metrics that allow for both positive and negative effects of VCD, are largely absent.

There is an urgent need and an opportunity for public and private investors in VCD to promote the adoption of an asset-based approach to the design and implementation of value-chain initiatives, based on welldefined impact models, and to the development of sound metrics that help demonstrate under which conditions VCD generates high poverty impact. Recent work by an international coalition of development practitioners and researchers highlights the opportunities and the challenges for the application of an asset-based approach to VCD (Box 2.4).

\section{$V C D$ requires adequate linking of technical, business, and financial services.} In addition to successful collaboration between public and private sectors and civil society, pro-poor VCD requires a combination of technical, business, and financial services. Some of these services are available from within the chain, particularly those that help improve quality or efficiency. Such "embedded services," typically provided by downstream actors to their upstream business partners, have the advantage of focusing on clearly identified needs and upgrading opportunities in the chain. On the other hand, certain services may not be readily available from within the chain, especially those that help improve environmental and social performance or that address long-term issues related to capacity building and skills development among the poor. These services may need to be sourced from external service providers, such as government agencies, NGOs, development projects, and consulting firms. The diverse nature of the services needed poses a challenge to their effective and efficient delivery. Technical services related to production and, to a lesser extent, processing technologies tend to be readily available for traditional products, from either downstream actors or external service providers. Financial services may be provided in the form of advance payments or credits within the chain, or through government programs and microfinance projects from outside of the chain. Usually, 


\section{Box 2.4 International collaboration to design an asset-based approach to value-chain development assessment}

Between 2008 and 2011, an international group of development practitioners and researchers, representing Bioversity International, the Tropical Agricultural Research and Higher Education Center (CATIE), Catholic Relief Services (CRS), the World Agroforestry Centre (ICRAF), HELVETAS Swiss Intercooperation, Lutheran World Relief (LWR), Mennonite Economic Development Associates (MEDA), Swisscontact, TechnoServe, and Winrock's Wallace Center, among others, collaborated on the design and testing of the 5Capitals Toolkit-an asset-based approach assessing the poverty impacts of VCD (see Donovan and Stoian 2010). In collaboration with local NGOs and consultants, and with financial support from the Ford Foundation, the toolkit was designed and validated through 23 case studies in Latin and North America, Africa, and Asia. The aim was to design a tool that would (1) assess the impact of a whole set of VCD interventions, rather than that of a particular intervention; (2) consider changes in assets among both households and the enterprises that maintained links with them; and (3) differentiate between the impacts of the combined VCD interventions and those induced by external factors. Experiences gained in tool testing demonstrated the potential of an asset-based approach to VCD assessment, along with related challenges. Case-study collaborators agreed that (1) such an approach is very useful to gain in-depth insight on VCD-related poverty impacts; (2) the focus on both household and enterprise assets sheds additional light on poverty impacts; (3) the context analysis as the first step of the methodology is critical to isolate VCD-related impact from contextinduced change; and (4) the results of impact assessment have highest value when used for redesigning VCD interventions. At the same time, they found that this approach (1) implies investments of human and financial resources that are reasonable but not low-cost, (2) requires a flexible handling of the enterprise assessment due to the varied nature of "linked enterprises," and (3) depends on systems thinking to make the most out of it. The final version of the toolkit (in English and Spanish) and an edited case study volume are available on the CATIE and ICRAF websites (Donovan and Stoian 2012).

Source: Authors

however, they are not available to highly resource-constrained smallholders. Business services often turn out to be the Achilles' heel in VCD as specialized business service providers for the rural sector are largely absent. A further challenge for VCD-related services is their provision in an isolated 
fashion. Service providers are typically specialized in one of these three types of services and rarely make an effort to partner with those who provide complementary services. Effective and efficient services for VCD require a sound demand analysis and a concerted approach to the delivery of technical, business, and financial services that are well-linked and complement each other in a logical fashion. Following the subsidiarity principle, that is, that all functions in the chain should be performed on the "lowest" level possible, only those services that cannot be sourced from within the chain would be provided from outside of the chain.

\section{What We Still Need to Know and Do Differently}

Despite the increasing focus on poverty by governments, development agencies, and civil society organizations, and some tangible success stories, the number of rural people living in desperate conditions under various degrees of vulnerability remains high. Undoubtedly, we have advanced our understanding of poverty issues and there is a growing consensus on the importance of pro-poor interventions in value chains. There are a number of crucial issues on which our knowledge is still insufficient. In the absence of an asset-based approach to designing, implementing, and monitoring value-chain initiatives, related impact models and theories of change are incomplete. Under these conditions, it is virtually impossible to identify the best options for helping poor people to exit out of poverty, let alone to stay out of poverty. In addition to these knowledge gaps, there are a number of "action gaps" related to areas that require forms of engagement in value chains in addition to, or other than, those applied to date.

\section{Need for Improved Knowledge}

- How to determine value-chain readiness? If the goal of the intervention is to reduce vulnerability and lift people out of poverty, how can we determine whether poor households and their business organizations are ready to participate in VCD? Which minimum asset thresholds do they need to meet and, if not available, what are the best options to help them become value-chain ready?

- Can asset building at the level of smallholder enterprises spur asset building at the household level? Since business organization of smallholders is often considered a prerequisite for their successful participation in value chains, 
we need to understand under what conditions asset building at the level of the smallholder enterprises positively influences household assets and reduces vulnerability; and how VCD can help to create more synergy in this respect.

- How to ensure that assessing VCD impact is both effective and efficient? Current impact assessment of value-chain programs tends to be low-cost and fairly one-dimensional, whereas an asset-based approach to assessment yields more robust results while requiring higher investments. There is a clear need for experimenting with differentiated approaches to impact assessment; for example, the routine measuring of outputs, the assessing of outcomes to the extent possible, and full-fledged impact assessment through in-depth case studies. The Donor Committee for Enterprise Development (DCED), for example, recommends three "universal" impact indicators (scale, income, and jobs) for ongoing results measurement; at the same time, it acknowledges that this cannot replace rigorous impact assessments, nor evaluations, as these ask broader questions (Tanburn and Sen 2011).

- How best to use an asset-based approach for planning, implementing, and assessing VCD? This question is at the heart of any improvements in VCD. In particular, we need to understand what indicators within each asset type-typically including human, social, natural, physical, and financial capital - tell us the most about reducing poverty and vulnerability. Which proxies can be used to make assessment manageable and cost-effective? How do we adapt or tailor VCD to different contexts and varying asset levels in given populations? How can we best deal with nonlinear asset pathways (asset building followed by asset erosion or vice versa)?

- Which roles correspond to private, public, and civil society sectors in promoting VCD? What can the private sector do alone? Under what conditions will the private sector invest in the long term, or go the extra mile for pro-poor VCD? What can realistically be expected from private-sector initiatives, such as base of the pyramid, corporate social responsibility, or creating shared value? Where and how do public-private partnerships work best, and where are their limits? What is the specific role of NGOs in helping build assets beyond the contributions from public and private sectors? 


\section{Need for Improved Action}

- Account for the evolution of income and asset objectives. VCD programs need to account for the dynamics and variations of asset endowments and livelihood objectives among poor and vulnerable populations. Different measures are needed in each stage when following a pathway out of poverty from "(i) stabilizing household consumption/stemming asset loss, to (ii) smoothing household consumption/protecting assets, to (iii) smoothing household income/acquiring assets, to (iv) expanding household income/leverage assets, and to (v) stabilized income-generation and asset accumulation" (Fowler and Brand 2011).

- Differentiate between those who are value-chain ready and those who are not. Market-based interventions work for those who meet minimum asset thresholds and, therefore, are value-chain ready. Those who do not meet those thresholds require specific, nonmarket-based interventions to create the necessary preconditions for their participation in VCD. These include, but are not limited to, customized technical assistance and training to build human and social capital, rehabilitation of natural capital where eroded, investments in basic infrastructure and services, and resolution of land-tenure conflicts where they exist. These interventions fall outside the realm of VCD, but are critical for its success if the poorest sections of the rural population are to benefit.

- Follow logical sequence of asset building. There are plenty of examples of programs where donors have given processing equipment to farmer organizations, but the initiatives have failed because of lack of business skills. In many cases, human and social capital need to be built before considering investments in physical capital. In other cases, eroded natural capital needs to be rebuilt before meaningful business development is possible.

- Ensure synergies among public and private sectors and civil society promoting VCD. Based on the subsidiarity principle, public sector and civil society should only engage in those interventions that cannot be performed by the private sector. This requires determining which services can be provided from within the chain ("embedded services") and which need to be sourced from external service providers (in many cases government agencies or NGOs). For example, rather than donating equipment, donors might link farmers to credit agencies to buy the equipment. If necessary, agencies could subsidize the cost of credit. 
- Improve the quality of and the linking between technical, business, and financial services. In the absence of integrated service providers, we need to make major efforts to link technical, business, and financial services in ways that allow for meaningful asset building at household and smallholder-enterprise levels. At the same time, we need to ensure that the linking of these services is geared to the requirements identified by the chain actors rather than outside agents from the public sector or civil society.

- Create awareness among donors and development practitioners about the advantages of adopting an asset-based approach to the design, implementation, and assessment of VCD. There is a need to provide evidence that the increased costs and complexity of an asset-based approach are outweighed by tangible benefits in terms of higher impact on poverty reduction, livelihood resilience, and viability of smallholder enterprises.

- Promote comprehensive strategies for rural development. There is both a need and an opportunity to combine VCD with other approaches to rural development, such as sustainable rural livelihoods, territorial development, and investments in rural infrastructure and services.

- Innovate in partnerships for joint learning and continuous improvement. The diverse nature of stakeholders in VCD provides a great opportunity for joint learning. Each of them brings specific perspectives, skills, and experiences to the table, but we need to define appropriate forums and mechanisms for sharing and capitalizing on these. The outcome of such learning alliances and communities of practice will be highest if nurtured by genuine interest in learning and authentic commitment to continuous improvement.

\section{Conclusion}

Our current knowledge of the poverty impacts of VCD is limited. Regardless of whether related initiatives are driven by private, public, or civil society sectors, the use of sound metrics to determine their impact at both enterprise and household levels, and to isolate VCD from context-induced change, should be the rule rather than the exception. If VCD is to be effective in addressing rural poverty, it must embrace the complex needs and realities of the rural poor. This includes the recognition that market-oriented activities are important but not exclusive elements of rural livelihood strategies. Particular attention needs to be paid to the specific challenges and needs of the very poor, 
given their higher risk and vulnerability. Otherwise, there is a substantial risk that pro-poor VCD does not live up to expectations and causes undue tradeoffs in the livelihood strategies of the rural poor.

An asset-based approach to the design, implementation, and assessment of VCD is a powerful vehicle to address these challenges and risks. Not only does it provide an appropriate measure of the multiple dimensions of poverty and vulnerability, but it also helps to determine which households and smallholder enterprises are ready for VCD, and which require specific preparatory interventions to become value-chain ready. An asset-based approach to VCD comes at a price, however. Related planning, data collection, and analysis are relatively time-consuming, complex, and costly. At the same time, such an approach helps forgo higher expenses to mitigate unintended effects of interventions in value chains. It provides public-sector and civil society organizations with the necessary information to justify the investment of taxpayers' money, and holds the potential to improve the environmental and social credentials of private-sector companies pursuing base of the pyramid, corporate social responsibility, creating shared value, or similar strategies.

VCD is not a panacea to rural development. When seeking impact beyond poverty reduction on resilience of livelihoods and ecosystems, it needs to be paired with complementary approaches. Comprehensive strategies for rural development would include improvements in local infrastructure and services, political-legal frameworks, food security, local markets for agricultural and forest products, and income generation through services and off-farm employment. Appropriate design, implementation, and monitoring and evaluation of such strategies, again, will best be achieved by pursuing an assetbased approach.

Much remains to be learned about the best possible design and implementation of value-chain programs and pertinent combinations with other approaches. Undoubtedly, however, an asset-based approach to pro-poor VCD is a critical element of such strategies. Governments, donors, development agencies, NGOs, and private-sector agents committed to poverty reduction will need to invest in pilot projects, tool development, and capacity building; engage in multistakeholder platforms for joint learning; and commit to continuous improvement. Without the adoption of an asset-based approach to VCD, poor households and smallholder enterprises in the upstream segments of the chain will continue to be exposed to high uncertainty and risk and, in particular, to potentially harmful trade-offs between value-chain optimization and resilience at the household and business levels. 


\section{References}

Altenburg, T. 2007. Donor Approaches to Supporting Pro-poor Value Chains. Report prepared for the Donor Committee for Enterprise Development - Working Group on Linkages and Value Chains. Bonn, Germany: German Development Institute. www.value-chains.org/dyn/bds/ docs/568/DonorApproachestoPro-PoorValueChains.pdf.

Arora, S., and H. Romijn. 2009. Innovation for the Base of the Pyramid: Critical Perspectives from Development Studies on Heterogeneity and Participation. Maastricht, the Netherlands: United Nations University / Maastricht Economic and Social Research and Training Centre on Innovation and Technology. www.merit.unu.edu/publications/wppdf/2009/wp2009-036.pdf.

Charette, D. 2011. A Portfolio Approach to Value Chain Development Programs. Microreport \#169. Washington, DC: United States Agency for International Development.

DFID (Department for International Development) and SDC (Swiss Agency for Development and Cooperation). 2008. A Synthesis of the Making Markets Work for the Poor (M4P) Approach. Berne, Switzerland: SDC.

Donovan, J., and N. Poole. 2011. Asset Building in Response to Value Chain Development: Evidence from Specialty Smallholder Coffee Producers in Nicaragua. ICRAF Working Paper 138. Nairobi, Kenya: World Agroforestry Centre.

Donovan, J., and D. Stoian (with contributions from I. Antezana, J. Belt, S. Clark, M. Harper, N. Poole, et al.). 2010. Assessing the Impact of Value Chain Approaches on Rural Poverty. Methodological Guidelines for Development Practitioners and Private Sector Representatives. Turrialba, Costa Rica: Centro Agronómico Tropical de Investigación y Enseñanza.

Donovan, J., and Stoian, D. 2012. 5Capitals: A Tool for Assessing the Poverty Impacts of Value Chain Development. Technical Series, Technical Bulletin no. 55, Rural Enterprise Development Collection No. 7. Turrialba, Costa Rica: Tropical Agricultural Research and Higher Education Center (CATIE).

Fowler, B., and M. Brand. 2011. Pathways Out of Poverty: Applying Key Principles of the Value Chain Approach to Reach the Very Poor. Discussion Paper / Microreport \#173. Washington, DC: United States Agency for International Development.

Haddad, L., J. Lindstrom, and Y. Pinto. .2010. “The Sorry State of M\&E in Agriculture: Can People-Centred Approaches Help?” IDS Bulletin 41 (6): 6-25.

Humphrey, J., and L. Navas-Alemán. 2010. Value Chains, Donor Interventions and Poverty Reduction: A Review of Donor Practice. IDS Research Report 63. Brighton, UK: Institute of Development Studies.

Jones, H. 2011. Taking Responsibility for Complexity: When is a Policy Problem Complex, Why Does it Matter, and How Can it be Tackled? ODI Briefing Paper 68. London: Overseas Development Institute. 
Kula, O., J. Downing, and M. Field. 2006. "Value Chain Programmes to Integrate

Competitiveness, Economic Growth and Poverty Reduction." Small Enterprise Development 17 (2): $23-35$.

McKay, A. 2009. Assets and Chronic Poverty: Background Paper. Chronic Poverty Research Centre Working Paper 100. Brighton, UK: University of Sussex. www.chronicpoverty.org/uploads/ publication_files/WP100\%20McKay_1.pdf.

Porter, M. E., and M. R. Kramer. 2011. "Creating Shared Value: How to Reinvent Capitalism and Unleash a Wave of Innovation and Growth." Harvard Business Review (Jan-Feb): 2-17.

Stoian, D., and J. Donovan. 2007. "Value Chain Development from a Livelihoods Perspective: A Multi-chain Approach for Coffee and Cacao Producing Households in Central America." In Utilisation of Diversity in Land Use Systems: Sustainable and Organic Approaches to Meet Human Needs, edited by E. Tielkes, 200. Göttingen, Germany: Cuvillier.

Tanburn, J., and N. Sen. 2011. Why Have a Standard for Measuring Results? Progress and Plans of the Donor Committee for Enterprise Development. London: Donor Committee for Enterprise Development.

UN (United Nations). 2011. The Millennium Development Goals Report 2011. New York.

UNIDO (United Nations Industrial Development Organization). 2011. Pro-poor Value Chain

Development: 25 Guiding Questions for Designing and Implementing Agroindustry Projects. Vienna, Austria.

Webber, C. M., and P. Labaste. 2010. Building Competitiveness in Africa's Agriculture: A Guide to Value Chain Concepts and Applications. Washington, DC: World Bank. 